\title{
Different Approaches to FT-IR Microspectroscopy on $X$-ray Exposed Human Cells ${ }^{\dagger}$
}

\author{
Marianna Portaccio 1, Federico Manganello ${ }^{2}$, Roberta Meschini ${ }^{2}$, Ines Delfino ${ }^{2}$, \\ Valerio Ricciardi ${ }^{1,3}$ and Maria Lepore ${ }^{1, *}$ \\ 1 Dipartimento di Medicina Sperimentale, Università della Campania “Luigi Vanvitelli”, 80138 Napoli, Italy; \\ mariannabiancaemanuela.portaccio@unicampania.it (M.P.); valerio.ricciardi@unicampania.it (V.R.) \\ 2 Dipartimento di Scienze Ecologiche e Biologiche, Università della Tuscia, 01100 Viterb, Italy; \\ manganello.f@gmail.com (F.M.); meschini@unitus.it (R.M.); delfino@unitus.it (I.D.) \\ 3 Istituto Nazionale di Fisica Nucleare-Sezione di Napoli, 80126 Napoli, Italy; vricciardi@na.infn.it \\ * Correspondence: maria.lepore@unicampania.it; Tel.: +39-081-5665839 \\ + Presented at the 6th International Electronic Conference on Sensors and Applications, 15-30 November \\ 2019; Available online: https://ecsa-6.sciforum.net/.
}

Published: 14 November 2019

\begin{abstract}
Fourier-Transform Infrared microspectroscopy ( $\mu$ FT-IR) has been usefully applied in the analysis of the complex biological processes occurring during X-ray radiation-cell interaction. Different experimental approaches are available for FT-IR spectra collection (transmission, attenuated total reflection (ATR), and transflection modes) from cells samples. Recently, some problems have been raised about the role of transmitted and reflected components of the infrared beam in transflection mode. For this reason, we investigated two different transflection approaches for collecting spectra from cells exposed to X-ray. In the former approach, cells were grown on MirrIR slides, and for the second approach, cell pellets were prepared. In both cases, SH-SY5Y neuroblastoma cells were used. X-ray exposure was performed at doses of 2 and $4 \mathrm{~Gy}$. Spectra were obtained by using both the approaches in the $600-4000 \mathrm{~cm}^{-1}$ spectral range from exposed and notexposed samples. The main contributions from proteins, lipids, carbohydrates, and DNA were clearly evidenced in spectra obtained with the two different acquisition approaches. A comparison among them has been also reported.
\end{abstract}

Keywords: neuroblastoma cells; Fourier-Transform Infrared microspectroscopy; X-ray radiation

\section{Introduction}

Fourier-Transform Infrared microspectroscopy ( $\mu$ FT-IR) is nowadays considered a valuable tool for investigating biochemical changes occurring in cells during the interaction with external agents [1]. In particular, $\mu$ FT-IR has been usefully applied in the analysis of the complex biological processes occurring during X-ray radiation-cell interaction [2,3]. Different experimental approaches are available for FT-IR spectra collection (transmission, attenuated total reflection (ATR), and transflection modes) on cells samples. Transflection-mode FTIR spectroscopy is particularly used for this kind of samples due to the relatively low cost of required substrates compared to transmission windows, and a higher absorbance due to a double pass through the same sample approximately doubling the effective path length. Recently, some questions have been raised about the role of transmitted and reflected components of the infrared beam in transflection mode [4,5]. For this reason, we started investigating two different transflection approaches for collecting spectra from cells exposed to X-ray. In the former approach, cells were grown on MirrIR slides, a specific reflection FT-IR spectroscopy microscope slide; for the second approach cell pellets were prepared. In both cases, SH-SY5Y neuroblastoma cells were used. 
X-ray exposure was performed at doses of 2 and 4 Gy. FT-IR absorption spectra were obtained by using both the approaches in the $600-4000 \mathrm{~cm}^{-1}$ spectral range from exposed and not-exposed (control) samples. The main contribution from proteins, lipids, carbohydrates, and DNA has been clearly evidenced and assigned. A comparison among spectra obtained with the different experimental approaches has been also reported.

\section{Methods}

\subsection{Materials}

DMEM medium, fetal bovine serum, penicillin, streptomycin, L-glutamine, and formaldehyde were provided by Sigma-Aldrich Co. and used without any further treatments. SH-SY5Y (American Type Culture Collection, Manassas, VA, USA) is a human cell line subcloned from a bone marrow biopsy taken from a four-year-old female with neuroblastoma.

\subsection{Sample Preparation and Treatment}

SH-SY5Y cells were cultured in vitro in DMEM medium, supplemented with $15 \%$ fetal bovine serum, $1 \%$ penicillin, $1 \%$ streptomycin, and $1 \% \mathrm{~L}$-glutamine. They were grown at $37{ }^{\circ} \mathrm{C}, 5 \% \mathrm{CO}_{2}$ in $25 \mathrm{~cm}^{2}$ flasks. Two types of samples were prepared: For the first (slide-cells), the cells were seeded on MirrIR slides $\left(25 \times 25 \mathrm{~mm}^{2}\right)$ (Kevley Technologies, Chesterland, Ohio), a specific reflection FT-IR spectroscopy microscope slide, nested into petri dishes $(60 \mathrm{~mm}$ diameter); for the second approach (drop-cells) cell pellets were prepared. The number of cells was $\sim 4 \times 10^{5}$ for the slide-cells samples, since in these conditions, cells were not confluent as to leave sufficient inter-cellular spaces for measurement of the background signal, and $\sim 2 \times 10^{6}$ cells/pellet were used for the drop-samples.

X-ray irradiation was performed at room temperature, using a Gilardoni MGL 200/8D machine operating at $250 \mathrm{kVp}$ and $6 \mathrm{~mA}$ (dose rate $60 \mathrm{cGy} / \mathrm{min}$ ). Both types of cellular samples were exposed to various doses of X-rays (2, 4 Gy), and then investigated together with unexposed cells ( $0 \mathrm{~Gy})$.

After X-ray exposure, the cells grown on MirrIR slides were fixed in a 3.7\% formaldehyde PBS solution for $20 \mathrm{~min}$ at room temperature, and then briefly washed in distilled water for $3 \mathrm{~s}$ to remove the residue PBS from the surface of the cells. Subsequently, the samples were dried under ambient conditions and stored in a desiccator until spectral analysis. Cell pellets after the exposure were centrifuged for $8 \mathrm{~min}$ at $1500 \mathrm{rpm}$. The supernatant was aspirated, and the pellet resuspended in 300 $\mu \mathrm{L}$ of $\mathrm{NaCl} 0.9 \%$ until spectra acquisition.

\subsection{FT-IR Micro-Spectroscopy Measurements}

IR absorption spectra of the cells samples were acquired at room temperature, using a Spectrum One FTIR (PerkinElmer, Shelton, CT, USA) spectrometer equipped with a Perkin Elmer Multiscope system infrared microscope and an MCT (mercury cadmium telluride) FPA (focal-plane-array) detector. For the slide-cells samples, the measurements were performed on cells grown on $25 \times 25$ $\mathrm{mm}^{2}$ MirrIR slides in transflection mode. Spectra were collected within an aperture of $100 \times 100 \mu^{2}$. The background signal was acquired in a region of the slide free of cells. Every slide was examined in different regions, and multiple spectra were acquired for each position. The signal was collected in the spectral region between 4000 and $600 \mathrm{~cm}^{-1}$ using 16 scans with a spectral resolution of $4 \mathrm{~cm}^{-1}$ and a $5 \mathrm{~s}$ acquisition time for each spectrum at room temperature.

For the drop-cells samples, a drop of $3 \mu \mathrm{L}$ volume was taken from the $0.9 \% \mathrm{NaCl}$ cells suspensions irradiated at various doses and deposited on a normal microscope slide coated with aluminum paper, which has the task of reflecting the IR light after the passage through the sample. The so-obtained slides were left to dry at ambient condition and subsequently analyzed with the spectrometer following the same procedure used for the slide-cells samples. 


\subsection{Data Analysis}

\subsubsection{Preliminary Process}

The whole dataset of the spectra detected from cells was preliminarily processed by subtracting the corresponding background spectrum from the measured one and, subsequently, noise corrections was performed on the whole data set by a numerical procedure based on wavelet algorithms ("MATLAB Wavelet Toolbox", MathWorks Inc., Natick, MA, USA) [6-8]. The signal was recalculated from detail components up to the nine level. Then, a piecewise baseline correction was performed as usually done to eliminate the possible contributions due to scattering or absorption by the supporting substrate in transmission or transflection type IR spectroscopy [9]. After this step, the spectra were processed via vector normalization procedure in order to have comparable intensities, using Standard Normal Variate method $[9,10]$.

\subsubsection{Average Spectra}

Average spectra were obtained for each type of samples and positions of principal peaks and their absorbance values were evaluated. The related graphic elaborations were carried out using MATLAB (MathWorks Inc., Natick, MA, USA) software.

\section{Results and Discussion}

\subsection{Control Spectra}

FT-IR spectra of SH-SY5Y neuroblastoma cells consist of several bands arising from the vibrational modes of the biologic molecules of cells constituents (lipids, proteins, DNA, etc.). In Figure 1 average spectra of unexposed samples, for both slide- and drop-cells, obtained in the region $900-3600 \mathrm{~cm}^{-1}$, are reported. The spectra appear to be divided into two principal zones with different visible peaks. The range from 2800 to $3600 \mathrm{~cm}^{-1}$ (Figure 1A,C) is generally indicated as high wavenumber region (HWR) and presents bands that are due to the contribution of proteins, lipids, and carbohydrates. In the so-called fingerprint region $\left(900-1800 \mathrm{~cm}^{-1}\right.$ ) (Figure 1B,D), different peaks that are representative of proteins and nucleic acids are clearly visible. In Table 1, the assignments of the main peaks are reported according to literature $[2,3,11-13]$.

Table 1. FT-IR peaks observed in the spectrum of control cells, with assignments in accordance with the data reported in the literature [2,3,11-13]; abbreviation: as = asymmetric, $s=$ symmetric, $v=$ stretching, $\delta=$ bending, $s c=$ scissoring, $v b r=$ vibration, $a$. a. $=$ free amino acids .

\begin{tabular}{|c|c|c|c|c|}
\hline Peak & \multicolumn{4}{|c|}{ ASSIGNMENT } \\
\hline $\mathrm{cm}^{-1}$ & DNA/RNA & Protein & Lipid & Carbohydrate \\
\hline $3200-3500$ & & & & $\mathrm{O}-\mathrm{H} v$ \\
\hline $3200-3500$ & & Amide A (-N-H v) & & $\mathrm{O}-\mathrm{H} v$ \\
\hline$\approx 3150$ & & $-\mathrm{NH}_{3}{ }^{+}$as. $v$ (a. a.) & & \\
\hline$\approx 2960$ & & $\mathrm{CH}_{3}$ as. $\mathrm{N}$ & $\mathrm{CH}_{3}$ as. $v$ & \\
\hline$\approx 2920$ & & & $\mathrm{CH}_{2}$ as. $v$ & \\
\hline$\approx 2870$ & & $\mathrm{CH}_{3} \mathrm{~s} . \mathrm{v}$ & $\mathrm{CH}_{3} \mathrm{~s} . v$ & \\
\hline$\approx 2850$ & & & $\mathrm{CH}_{2}$ s. $v$ & \\
\hline$\approx 1650$ & & Amide I $(\mathrm{C}=\mathrm{O} v, \mathrm{C}-\mathrm{N} v)$ & & \\
\hline$\approx 1540$ & & Amide II (C-N v, C-NH ס) & & \\
\hline$\approx 1450$ & & $\mathrm{CH}_{3}$ as. $\delta, \mathrm{CH}_{2}$ sc. & $\mathrm{CH}_{3}$ as. $\delta, \mathrm{CH}_{2}$ sc. & \\
\hline$\approx 1400$ & & $\mathrm{COO}-\mathrm{s} . \mathrm{v}$ & & \\
\hline$\approx 1250$ & $\mathrm{PO}_{2}^{-}$as. $\mathrm{N}$ & $\mathrm{C}-\mathrm{O}-\mathrm{P} v$ & & \\
\hline$\approx 1080$ & $\mathrm{PO}_{2}^{-}$s. $v$ & $\mathrm{C}-\mathrm{O}-\mathrm{P} v$ & & \\
\hline
\end{tabular}



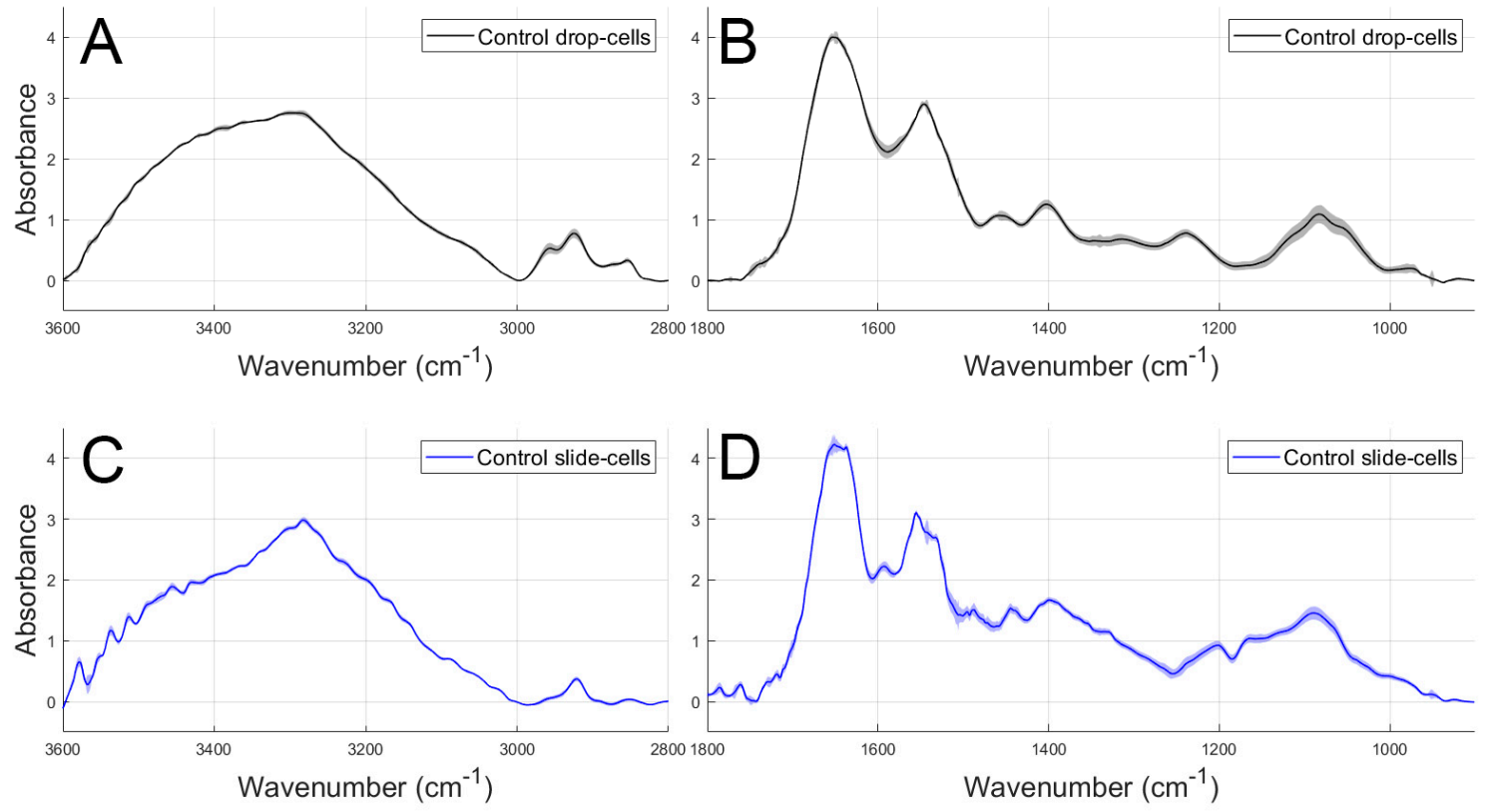

Figure 1. Average spectra of non-exposed cells samples: Drop-cells sample spectrum in the range (2800-3600 $\left.\mathrm{cm}^{-1}\right)(\mathbf{A})$ and in the range $\left(900-1800 \mathrm{~cm}^{-1}\right)(\mathbf{B})$, respectively; slide-cells sample spectrum in the range (2800-3600 $\left.\mathrm{cm}^{-1}\right)$ (C) and in the range $\left(900-1800 \mathrm{~cm}^{-1}\right)(\mathbf{D})$, respectively; the break at (1800$8800 \mathrm{~cm}^{-1}$ ) hides a region without interesting signals from biological molecules. Data presented as Mean \pm SEM.

In the HWR region, it is possible to observe lower absorbance values for the peaks in the range $\left(3200-3500 \mathrm{~cm}^{-1}\right)$ for the slide-cells samples; similarly, the peaks linked mainly to the stretching of the $-\mathrm{CH}_{2}$ and $-\mathrm{CH}_{3}$ groups in the range $\left(2800-3000 \mathrm{~cm}^{-1}\right)$ presents lower absorbance values for the slidecells samples. In the fingerprint region, some significant differences are visible: Higher absorbance values are detected for the slide-cells samples in the region (1500-1300 $\left.\mathrm{cm}^{-1}\right)$, with peaks mainly attributed to proteins and lipids. The peaks centered at $\approx 1450 \mathrm{~cm}^{-1}$ and $\approx 1250 \mathrm{~cm}^{-1}$ in the drop-cells spectrum, attributed to $-\mathrm{CH}_{2}$ and $-\mathrm{CH}_{3}$ bending of lipids and proteins and asymmetric $-\mathrm{PO}_{2}{ }^{-}$ stretching vibrations of the DNA phosphodiester, respectively, appears to be shifted to lower wavenumbers, to $\approx 1480 \mathrm{~cm}^{-1}$ and $\approx 1200 \mathrm{~cm}^{-1}$, in the slide-cells spectrum. The peak at $\approx 1080 \mathrm{~cm}^{-1}$, also attributed to $-\mathrm{PO}_{2}{ }^{-}$stretching vibrations of the DNA, presents higher absorbance for the slide-cells spectrum in respect to the drop-cells one. The SEM values (black and blue shadows in Figure), calculated for every wavenumber, show that the greater variability between spectra of the same sample type is present in the range $2800-3000 \mathrm{~cm}^{-1}$ and in the fingerprint region, in particular for the range $1200-1400 \mathrm{~cm}^{-1}$ and for the band at $\approx 1080 \mathrm{~cm}^{-1}$, for both drop- and slide-samples.

\subsection{Irradiated Spectra}

In Figure 2, average spectra of 2 Gy dose exposed samples, for both slide- and drop-cells, obtained in the range $2800-3600 \mathrm{~cm}^{-1}$ (Figure 2A,C) and is $900-1800 \mathrm{~cm}^{-1}$ (Figure 2B,D), respectively, are reported. In the HWR region, it is possible to observe, as in the case of the control spectra, lower absorbance values for the peaks in the range $\left(3200-3500 \mathrm{~cm}^{-1}\right)$ and $\left(3000-2800 \mathrm{~cm}^{-1}\right)$ for the slide-cells samples. The same is observed for the spectra irradiated at $4 \mathrm{~Gy}$ dose (not shown). In the fingerprint region, a shift towards lower wavenumbers is detected for the peak at $\approx 1450 \mathrm{~cm}^{-1}$ in the slide-cells for both 2 Gy and 4 Gy irradiated samples, as already observed in the control sample; also, the peak centered at $\approx 1250 \mathrm{~cm}^{-1}$ in the drop-cells spectrum presents a shift to $\approx 1280 \mathrm{~cm}^{-1}$ in the slide-cells spectrum, for both doses. The average drop-cells spectrum for the 4 Gy dose presents higher absorbance values in the range $\left(1000-1300 \mathrm{~cm}^{-1}\right)$ compared to that of the slide-cells, as for the control samples. Conversely, this difference is not visible for the spectra irradiated at $2 \mathrm{~Gy}$ dose. In terms of inner variability, the 2 Gy spectra for the drop-cells presents higher values of SEM (black and blue 
shadow in figure) in the range $3000-3600 \mathrm{~cm}^{-1}$, compared to samples of the same type at other doses and with the 2 Gy slide-cells spectrum. In the fingerprint region for both 2 and 4 Gy spectra, the greater variability is present for slide-cells spectra, in the range $1000-1400 \mathrm{~cm}^{-1}$.
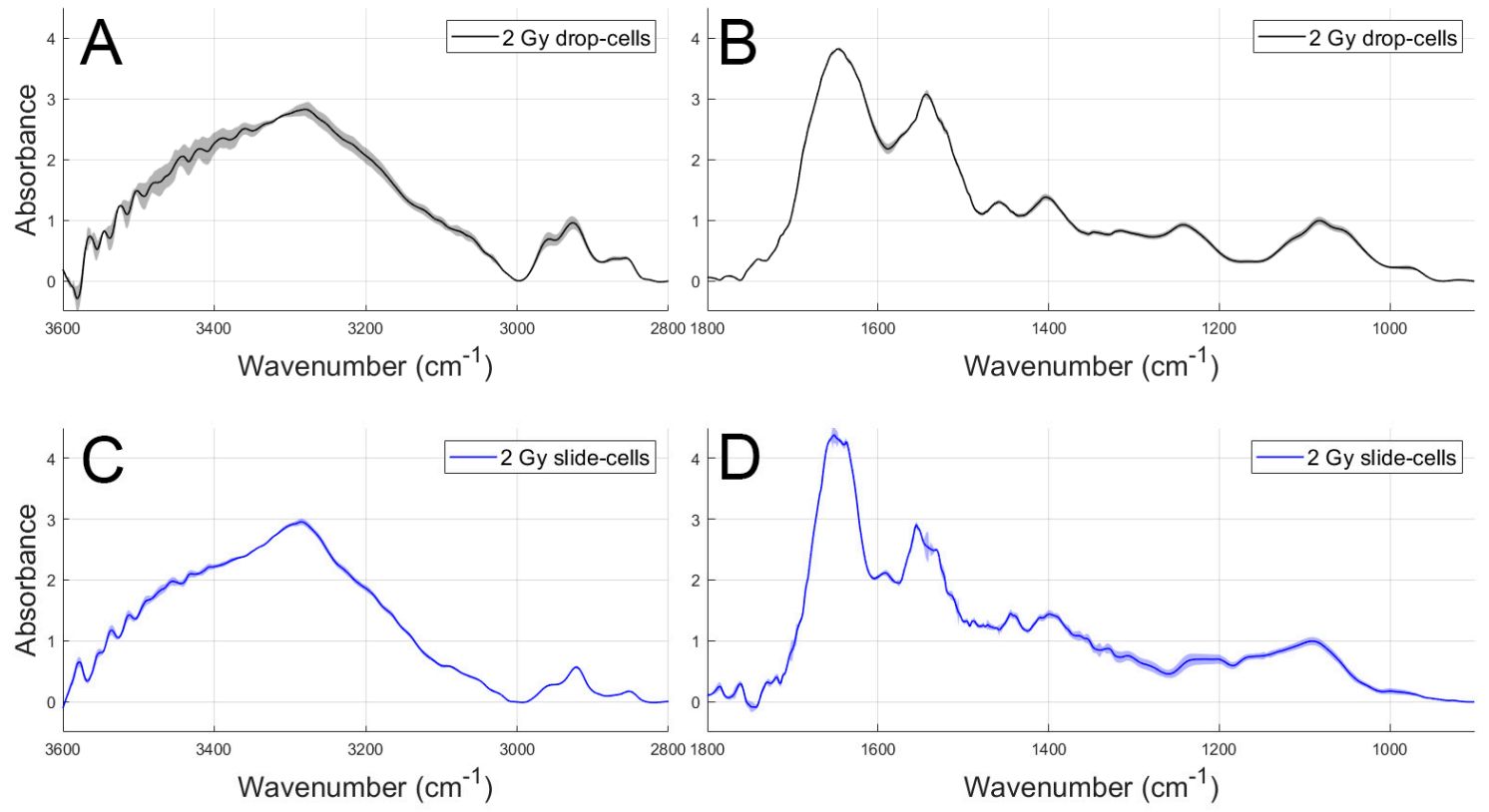

Figure 2. Average spectra of 2 Gy exposed cells samples: Drop-cells sample spectrum in the range (2800-3600 $\left.\mathrm{cm}^{-1}\right)(\mathbf{A})$ and in the range $\left(900-1900 \mathrm{~cm}^{-1}\right)($ B), respectively; slide-cells sample spectrum in the range $\left(2800-3600 \mathrm{~cm}^{-1}\right)$ (C) and in the range $\left(900-1900 \mathrm{~cm}^{-1}\right)(\mathbf{D})$, respectively; the break at (1900$2800 \mathrm{~cm}^{-1}$ ) hides a region without interesting signals from biological molecules. Data presented as Mean \pm SEM.

To take into account the internal variability of the spectra obtained by using the different approaches, the mean value of the SEM (in absolute value, for each wavenumber) for both drop- and slide-samples, for the HWR and fingerprint region, at the different irradiation doses were calculated (Table 2). This parameter allows us to have a preliminary estimate of the variations present in the spectra for the two procedures used for the preparation of the samples.

Table 2. Mean value of the SEM for the two types of samples and the different dose values.

\begin{tabular}{ccc}
\hline \multirow{2}{*}{ Dose } & \multicolumn{2}{c}{$\overline{\boldsymbol{S E M}}$} \\
\cline { 2 - 3 } & Drop-Cells & Slide-Cells \\
\hline Control & $0.05 \pm 0.02$ & $0.05 \pm 0.021$ \\
2 Gy & $0.05 \pm 0.03$ & $0.04 \pm 0.02$ \\
4 Gy & $0.03 \pm 0.01$ & $0.04 \pm 0.02$ \\
\hline
\end{tabular}

The inspection of the SEM values indicate that the two approaches are able to give similar results as far as concerns the signal variability for samples related to the same experimental conditions.

\section{Conclusions}

The results here reported indicate that the two investigated approaches enable the collection of spectra with analogous characteristics. This preliminary investigation suggests that the researcher can choose the modality which is more suitable in the execution of the particular experimental study to be carried out. 
Author Contributions: Conceptualization, M.L., V.R., and I.D.; methodology, V.R and M.L.; investigation, F.M., R.M., M.P.; data curation, V.R.; writing-original draft preparation, V.R. and M.L.; writing - review and editing, I.D., V.R., M.P., R.M., and M.L.

Funding: This research received no external funding.

Conflicts of Interest: The authors declare no conflict of interest.

\section{References}

1. Baker, M.J.; Trevisan, J.; Bassan, P.; Bhargava, R.; Butler, H.J.; Dorling, K.M.; Fielden, P.R.; Fogarty, S.W.; Fullwood, N.J.; Heys, K.A.; et al. Using Fourier transform IR spectroscopy to analyze biological material. Nat. Protoc. 2014, 9, 1771-1791, doi:10.1038/nprot.2014.110.

2. Gault, N.; Lefaix, J.L. Infrared microspectroscopic characteristics of radiation-induced apoptosis in human lymphocytes. Radiat. Res. 2003, 160, 238-250, doi:10.1667/RR3020.1.

3. Meade, A.; Clarke, C.; Byrne, H.; Lyng, F. Fourier transform infrared microspectroscopy and multivariate methods for radiobiological dosimetry. Radiat. Res. 2010, 173, 225-237, doi:10.1667/RR1836.1.

4. Bassan, P.; Lee, J.; Sachdeva, A.; Pissardini, J.; Dorling, K.M.; Fletcher, J.S.; Henderson, A.; Gardner, P. The inherent problem of transflection-mode infrared spectroscopic microscopy and the ramifications for biomedical single point imaging applications. Analyst. 2013, 138, 144-157, doi:10.1039/c2an36090j.

5. Mayerhöfer, T.G.; Pahlow, S.; Hübner, U.; Popp, J. Removing interference-based effects from the infrared transflectance spectra of thin films on metallic substrates: A fast and wave optics conform solution. Analyst. 2018, 143, 3164-3175, doi:10.1039/c8an00526e.

6. Camerlingo, C.; Zenone, F.; Gaeta, G.M.; Riccio, R.; Lepore, M. Wavelet data processing of micro-Raman spectra of biolofical samples. Meas. Sci. Technol. 2006, 17, 298-303, doi:10.1088/0957-0233/17/2/010.

7. Camerlingo, C.; Zenone, F.; Perna, G.; Capozzi, V.; Cirillo, N.; Gaeta, G.M.; Lepore, M. An investigation on micro-Raman spectra and wavelet data analysis for pemphigus vulgaris follow-up monitoring. Sensors 2008, 8, 3656-2664, doi:10.3390/s8063656.

8. Delfino, I.; Perna, G.; Lasalvia, M.; Capozzi, V.; Manti, L.; Camerlingo, C.; Lepore, M. Visible micro-Raman spectroscopy of single human mammary epithelial cells exposed to X-ray radiation. J. Biomed. Opt. 2015, 20, 035003, doi:10.1117/1.JBO.20.3.035003.

9. Lasch, P. Spectral pre-processing for biomedical vibrational spectroscopy and micro-spectroscopy imaging. Chemom. Intell. Lab. Syst. 2013, 117, 100-114, doi:10.1016/j.chemolab.2012.03.011.

10. Gautam, R.; Vanga, S.; Ariese, F.; Umapathy, S. Review of multidimensional data processing approaches for Raman and infrared spectroscopy. EPJ Tech. Instrum. 2015, 2, 8, doi:10.1140/epjti/s40485-015-0018-6.

11. Gault, N.; Rigaud, O; Poncy, J.L.; Lefaix, J.L. Infrared microspectroscopy study of $\gamma$-irradiated and $\mathrm{H}_{2} \mathrm{O}_{2-}$ treated human cells. Int. J. Radiat. Biol. 2005, 81, 767-779, doi:10.1080/09553000500515368.

12. Barth, A. Infrared spectroscopy of proteins. Biochim. Biophys. Acta 2007, 1767, 1073-1101, doi:10.1016/j.bbabio.2007.06.004.

13. Zelig, U.; Kapelushnik, J.; Moreh, R.; Mordechai, S.; Nathan, I. Diagnosis of cell death by means of Infrared Spectroscopy. Biophys. J. 2009, 97, 2107-2114, doi:10.1016/j.bpj.2009.07.026.

(C) 2019 by the authors. Licensee MDPI, Basel, Switzerland. This article is an open access article distributed under the terms and conditions of the Creative Commons Attribution (CC BY) license (http://creativecommons.org/licenses/by/4.0/). 